\title{
Initial presentation of Hodgkin's Lymphoma as Extradural Spinal Cord Compression: A case report
}

\author{
Rishav Mukherjee', Sampurna Chowdhury ${ }^{2}$ \\ 1,2 Post Graduate Trainee, Department of Medicine, Medical College, Kolkata
}

A 23 year old female presented with acute onset paraparesis. She denied any history of fever, weight loss or drenching night sweats. Neither did she have any obvious lymphadenopathy on general examination. Chest Xray was however suggestive of mediastinal widening and her MRI spine showed metastases with superior mediastinal SOL. Biopsy of this SOL ultimately revealed classical Hodgkin lymphoma. Thus this was a very unusual initial presentation of Hodgkin lymphoma presenting as Epidural Spinal Cord Compression. Hasenclever IPS score was 2. Patient was treated with radiotherapy followed by ABVD chemotherapy and achieved remission in 3months.

\section{Access this article online}

Website:

http://nepjol.info/index.php/AJMS DOI: 10.3126/ajms.v11i2.27477 E-ISSN: 2091-0576

P-ISSN: $2467-9100$

Key words: Hodgkin's Lymphoma; Paraparesis; Extradural Spinal Cord Compression

\section{INTRODUCTION}

Hodgkin's Lymphoma comprises of $10-15 \%$ of all Lymphoma cases and has a bimodal age distribution with a peak in the third decade as well as the seventh. The usual clinical presentations include:

a) Asymptomatic lymphadenopathy, most commonly above the diaphragm

b) Constitutional symptoms also known as the "B" symptoms - fever, weight loss and drenching night sweats presenting approximately $40 \%$ cases

c) As fever of unknown origin (intermittent fever - Pel Ebstein fever) in 35\%

d) SVC Syndrome due to Mediastinal Lymphadenopathy.

e) Patients may present with pruritus; pain at sites of nodal disease, precipitated by drinking alcohol, occurs in fewer than $10 \%$ of patients but is specific for Hodgkin lymphoma;

f) Back or bone pain may rarely occur.

A family history may be helpful; nodular sclerosis Hodgkin lymphoma (NSHL) has a strong genetic determinant and has often been previously diagnosed to run in the family. Hodgkin lymphoma is a potentially curable lymphoma.

Here we present a very rare presentation of Hodgkin's Lymphoma initially presenting as Paraparesis due to Compressive Myelopathy.

\section{CASE REPORT}

A 23 year old female started experiencing pins and needles on both her Upper Limbs for 2 days, this was followed by an acute painful retention of urine, followed by an acute onset Paraparesis. She also had a sense of band like tightness over her mid - chest. She denied having experienced any fever, weight loss or drenching night sweats. She denied having any chest pain or shortness of breath or hoarseness. Patient had no history of fever or diarrhoea or recent vaccination preceding this event. No history of TB/of TB contact. No history of trauma or any significant family history was elicited.

On examination, she was found to be mildly anaemic with no hepato- splenomegaly or obvious lymphadenopathy. 


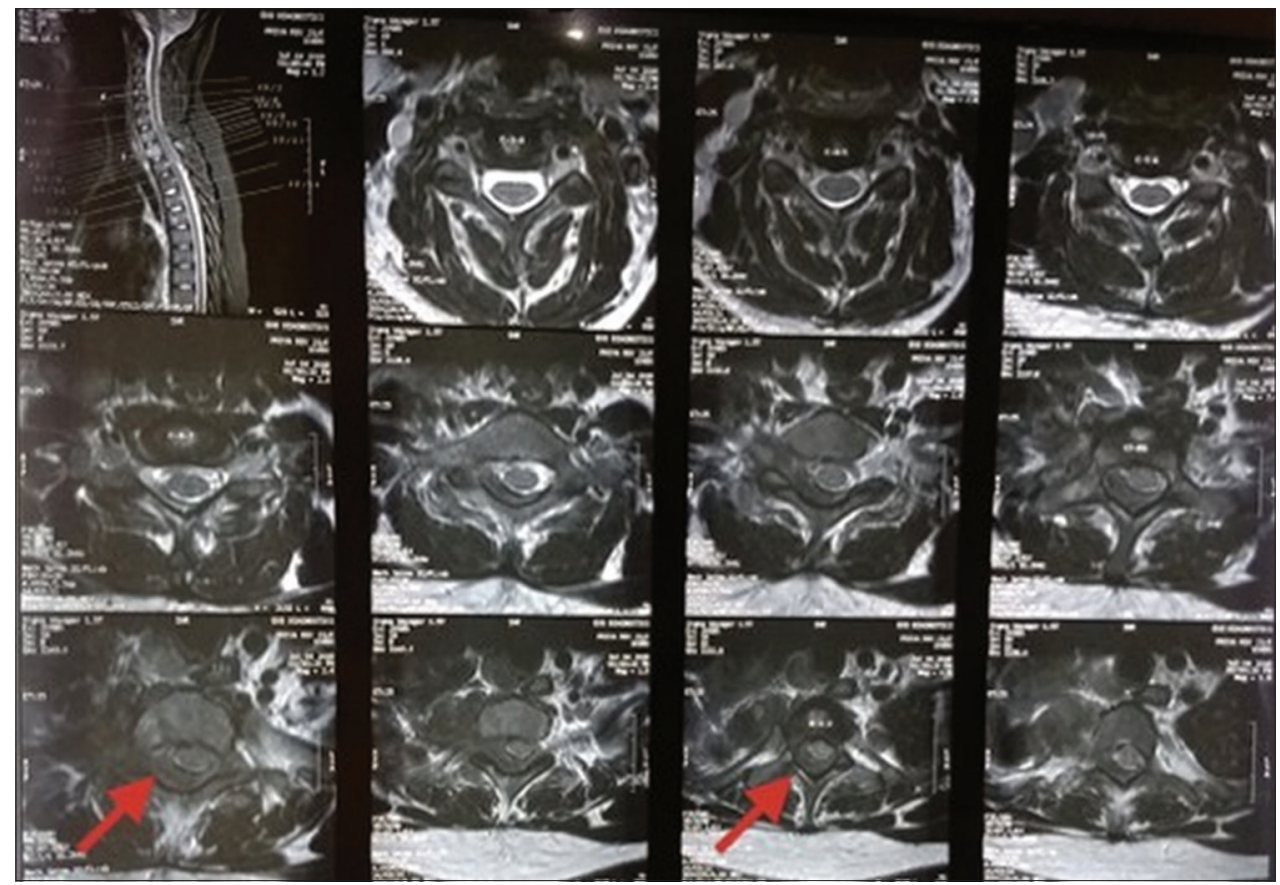

Figure 1: MRI Dorso- Lumbar spine (axial view) showing pressure effect on spinal cord with heterogenous enhancing areas on superior mediastinum.

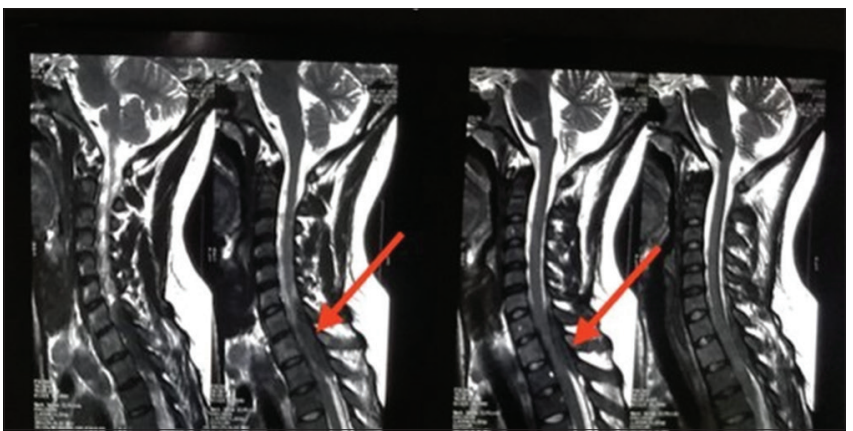

Figure 2: MRI Dorso lumbar spine (Sagittal view).

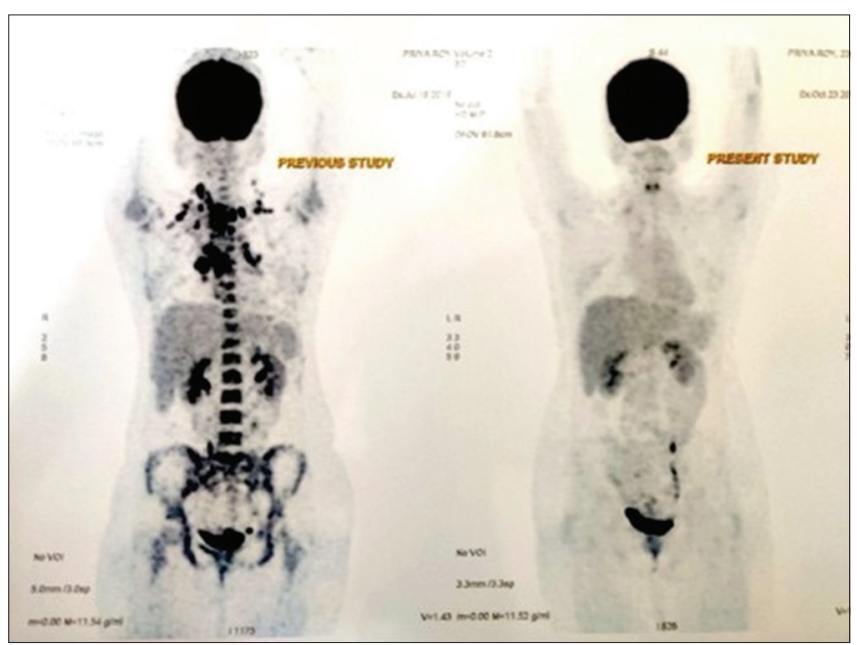

Figure 3: PET CT Scan showing response to therapy.

She also did not have peri orbital oedema or raised JVP or distended chest veins. Neurological examination revealed exaggerated Deep Tendon Reflexes in the lower limb with presence of ankle and knee clonus. Tone was increased in the lower limbs with a Power of $2 / 5$ bilaterally in the Lower limbs and a power of $4 / 5$ in B/L Upper limbs.

Definite sensory level was also present. Clinically lesion was localised to the lower cervical, upper thoracic level. Routine Lab Reports revealed a microcytic- hypochromic anaemia $\mathrm{Hb}=10.6 \mathrm{gm} / \mathrm{dl} \mathrm{ESR}=30 \mathrm{~mm} / \mathrm{hr}, \mathrm{TC}=4560 /$ micro litre with Neutrophils $76 \%$

Lymphocytes $16 \%$ Platelets $=365000 / \mathrm{cu} . \mathrm{mm}, \mathrm{LDH}=375$ (Ref. range 350-450) Albumin $=3.6 \mathrm{gm} / \mathrm{dl}$.USG abdomen was performed and revealed no hepato-splenomegaly or Retro - peritoneal lymphadenopathy. CXR was suggestive of mediastinal widening. MRI of Cervical and Thoracic Spine with contrast was done and it showed D1 vertebral Metastasis with epidural extension compressing upon the spinal cord from C6 to D3 level [Figures 1 and 2]. It also confirmed Mediastinal Lymphadenopathy and was suggestive of lymphoproliferative disorder. A CT guided Biopsy was obtained of the mediastinal SOL - Classical Hodgkin's Lymphoma was diagnosed on Immunohistochemistry. A bone marrow biopsy was also done which was normal.

Patient was started on Radio therapy with dexamethasone for the Spinal Compression. This was followed by ABVD regime.

She has responded to therapy and is able to walk without support. Her lymphoma too is currently in remission - from 
a Deauville score of 5 at diagnosis to a Deauville score of 1 in 3 months [Figure 3].

\section{DISCUSSION}

Hodgkin disease commonly presents with fever and lymphadenopathy with or without hepato-splenomegaly. Usually there is contiguous spread of disease via lymphatics with metastases occurring in advanced disease. Five percentage of HD may have spinal cord compression in advanced stages, however, initial presentation of Hodgkin's Disease as Extradural Spinal Cord Compression (ESCC) is extremely rare with less than $0.02 \%$ frequency. Mechanism of ESCC may be through direct extension of tumour mass through the intervertebral foramina. Most commonly it is found to afflict the thoracic spine.

\section{PRACTICAL IMPLICATIONS}

Although rare, Hodgkin's Disease can present initially as Compressive myelopathy without any features of disease elsewhere. Hence, must be included amongst the differentials for Neoplasms causing Spinal Cord Compression.

\section{REFERENCES}

1. Eichenauer DA, Aleman BMP, Andre M, Federico M, Hutchings T, Illidge $A$, et al. Hodgkin Iymphoma: ESMO Clinical Practice Guidelines for diagnosis, treatment and follow-up. Ann Oncol 2018;29(4):iv19-iv29.

2. Schnitzer B. Hodgkin Lymphoma Hematology/Oncology Clinics of North America 2009; 23(4):747-768.

3. Wood NL and Coltman CA. Localized Primary Extranodal Hodgkin's Disease. Ann Intern Med 1973; 78:113-118.

4. Grimm S and Chamberlain M. Hodgkin's Lymphoma: A Review of Neurologic Complications. Advances in Hematology 2011; 1-7.

5. Higgins SA and Peschel RE. Hodgkin's disease with spinal cord compression: A case report and a review of the literature.Cancer 1995;75(1):94-98.

6. Ghedira K, Matar N, Bouali S, Zehani A, Boubaker A and Jemel H. Hodgkin Lymphoma revealed by epidural spinal cord compression. The Journal of Spinal Cord Medicine 2018; 42(3):402-404.

\footnotetext{
Authors Contribution:

SC- Drafted the manuscript and did literature research; RM- Provided treatment to the patient in case and reviewed manuscript.

Work Attributed to:

Department of Medicine, Medical College, Kolkata

Orcid ID:

Dr. Rishav Mukherjee - (D) https://orcid.org/0000-0001-5883-2908

Dr. Sampurna Chowdhury- (1) https://orcid.org/0000-0002-5010-7565

Source of funding: No targeted study funding to be reported, Conflict of Interest: The authors have no disclosures to report relevant to the manuscript.
} 